\title{
Urea and Glucose Sensors Based on Ion Sensitive Field Effect Transistor with Photolithographically Patterned Enzyme Membrane
}

\author{
Satoru Shrono, Yoshio Hanazato and Mamiko Nakako
}

Central Research Laboratory, Mitsubishi Electric Co., Tsukaguchi-Honmachi, Amagasaki 661

\begin{abstract}
A polyvinylpyrrolidone (PVP) based photocrosslinkable polymer has been used to make an enzyme membrane on an ion sensitive field effect transistor (FET). An enzyme and a lysine-rich polypeptide were added to a PVP solution containing 2,5-bis(4'-azido-2'-sulfobenzal)-cyclopentanone as a photocrosslinking reagent. Using an integrated FET having two ion sensitive elements, an enzyme membrane on the gate surface of one of the two ion sensitive elements was formed by the spin-coating of the enzyme-PVP solution, followed by UV-irradiation on the gate area of the FET and development in a $3 \%$ glutaraldehyde solution. The method was used to make enzyme membranes for a urea sensitive and a glucose sensitive FET. Both sensors were evaluated by using a $0.3 \mathrm{ml}$ flow-through cell. The $100 \%$ response times were $25 \mathrm{~s}$ and $15 \mathrm{~s}$ for urea and glucose determination, respectively. The relative standard deviations for determination of urea and glucose with the sensors were less than $2 \%$ over the concentration range studied. The application of the urea sensitive FET to ex vivo serum assay is also described.
\end{abstract}

Keywords Biosensor, enzyme modified field effect transistor, ion sensitive FET, urea sensor, glucose sensor

Many experimental reports on the enzyme-modified field effect transistor (FET) have been published since the description of the penicillin sensitive enzymemodified FET by Caras and Janata. ${ }^{1}$ Theoretical consideration was offered on the influence of the buffering capacity of the analyte solution on the response of the enzyme-modified FET. ${ }^{2,3}$ While the penicillin sensitive enzyme-modified FET was composed of two discrete ion sensitive FET chips, one with an enzyme-immobilized membrane and the other without it, recently effort has been focused on the feasibility study of the monolithic enzyme-modified FET, using an integrated FET chip with more than two ion sensitive elements. 4 $^{-6}$ The monolithic enzymemodified FET requires that the enzyme membrane be patterned on specific areas of a small integrated FET chip. Some techniques have been proposed for the enzyme membrane patterning, e.g., the direct photolithographic patterning technique by the use of a watersoluble photocrosslinkable polymer ${ }^{6-8}$ and the technique based on the injection of enzyme-immobilizing mixtures into the pools formed on FET gates with a photosensitive film resist. 4,5 However, these techniques seem to need further improvements to get an enzymemodified FET having higher sensitivity and longer durability, and necessitating less tedious preparation work.

Of the patterning techniques reported, the direct photolithographic patterning one using a water-soluble photopolymer is likely to be preferable because of its simplicity. Poly (vinyl alcohol) having stilbazolium pendant groups $\mathrm{s}^{4,7,8}$ and a polyvinylpyrrolidone (PVP) based photopolymer containing 4,4'-diazidostilbene$2,2^{\prime}$-disulfonic acid ${ }^{8,10}$ as a photocrosslinking reagent have been so far attempted for this purpose. However, the two photopolymers are not fully satisfactory and some problems with these photopolymers need to be solved; for example, the limited amount of enzyme which is immobilized and the leakage of immobilized enzyme from the membrane ${ }^{7,9}$ (the advantages of the PVP based photopolymer over the PVA photopolymer has been discussed 6 ). To solve the problems the chemical crosslinking reaction by glutaraldehyde with proteins was employed in addition to the photoreaction, which resulted in considerable but not completely satisfactory improvements. ${ }^{9-11}$

Another photocrosslinking reagent, 2,5-bis(4'-azido2 '-sulfobenzal)-cyclopentanone (BASC) has been tried as a photocrosslinking reagent for PVP in attempts to achieve a better photosensitive polymer for the patterning of enzyme membranes on an FET. BASC has higher reactivity to the intense I-line $(365 \mathrm{~nm})$ of the mercury vapor lamp than the above mentioned diazido photocrosslinking reagent and thus was expected to be more suitable for the photolithographic enzyme membrane patterning. BASC-PVP mixtures have been found to give a well-defined enzyme membrane for glucose oxidase (GOD) and lipase. ${ }^{6}$ In 
this report a monofunctional urea sensitive and a monofunctional glucose sensitive FET sensor have been made using the photopolymer. A continuous flow cell with a smaller inner volume than that of the flow cell used formerly 9 has been designed to give a more rapid response and need less volume of a sample solution, and was used to evaluate the sensors. The urea and glucose sensors show rapid response, high sensitivity and long life. Medical application is also described.

\section{Experimental}

\section{Materials}

Urease (EC 3.5.1.5, from jack beans) obtained from P-L Biochemicals (Milwaukee, WI, USA) had an activity of $50 \mathrm{U} / \mathrm{mg}$. GOD ( $\beta$-D-glucose: oxygen oxydoreductase, EC 1.1.3.4, from Aspergillus niger, $29.3 \mathrm{U} / \mathrm{mg}$ ), bovine serum albumin (BSA) and poly-Llysine (average molecular weight: 25000) from Sigma (St. Louis, MO, USA) were used. Glutaraldehyde, $25 \%$ in water, were obtained from Ishizu Pharmaceutical (Osaka, Japan). PVP (average molecular weight: 360000) was purchased from Nakarai Chemicals (Osaka, Japan). The sodium salt of BASC was a gift from Mr. Miyazawa, Tokyo Ohka Kogyo (Kanagawa, Japan). Dialyzed serum was obtained from Cooper Biomedical (Malvern, PA, USA). All other chemicals were analytical reagent grade and were used without further purification. All solutions were made with distilled deionized water.

\section{Sensor construction}

An integrated ion sensitive FET having two hydrogen ion sensitive elements was fabricated from an epitaxially grown silicon wafer which had a p-type epitaxial layer, 8-12 ohm-cm (about $10 \mu \mathrm{m}$ in thickness), on a n-type substrate, 5-7 ohm-cm, with $(100)$ orientation. The gate insulator consists of a thermally grown silicon oxide layer, $50 \mathrm{~nm}$ in thickness, and a silicon nitride layer deposited by the low pressure chemical vapor deposition technique, 70 $\mathrm{nm}$. The chip size was $6.5 \times 5.0 \mathrm{~mm}$.

The structure of the enzyme-modified FET is illustrated in Fig. 1c. An ion sensitive FET (Fig. 1c, ISFET) is mounted on two epoxy laminates and encapsulated with an epoxy resin by the screen printing method. A thin gold film (G) is formed on the upper epoxy laminate, being used as a pseudo reference electrode. ${ }^{9}$ The ion sensitive FET surface was silanized with $\gamma$-aminopropyltriethoxysilane to improve the adhesive strength between the surface and an enzyme membrane. ${ }^{12}$ An immobilized-enzyme membrane (EM) was formed on the gate surface of one of the FET elements.

\section{Enzyme membrane}

A water-soluble photocrosslinkable polymer was

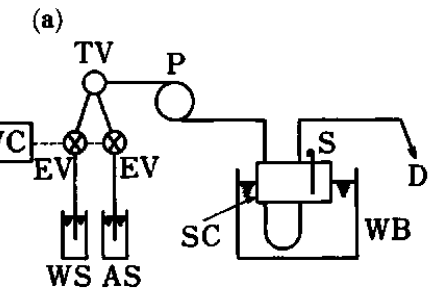

(c)
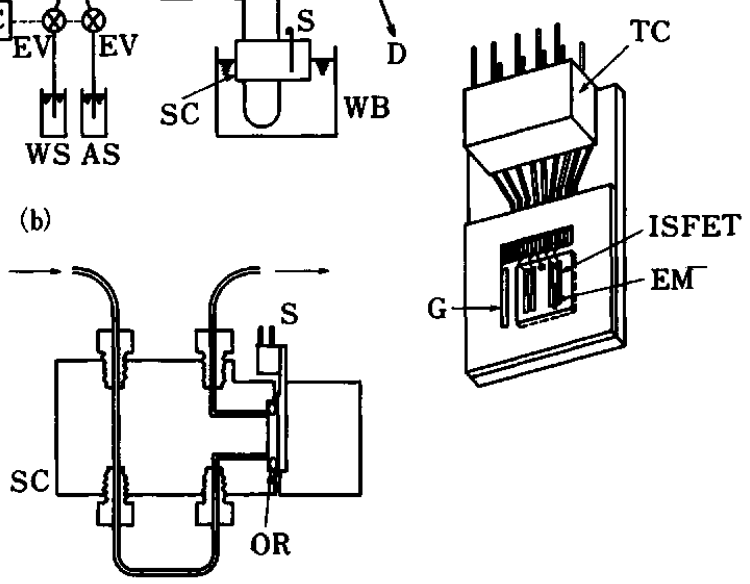

Fig. 1 Schematic diagram of continuous flow apparatus and structure of enzyme-modified FET. a) schematic diagram of continuous flow apparatus: $S$, enzyme-modified FET sensor; SC, sensor cell; WB, water bath; D, drainage; $P$, peristaltic pump; TV, three-way joint; EV, electrical valve; VC, valve controller; WS, washing solution; AS, analyte solution. b) detailed structure of flow-through cell: OR, rubber O-ring. c) structure of enzyme-modified FET (electrical insulation with epoxy resin is not shown here for simplicity, see text): ISFET, ion sensitive FET; $\mathrm{EM}$, enzyme membrane; G, thin gold film; TC, card edge connector.

prepared, adding $1 \mathrm{~g}$ of BASC to $100 \mathrm{ml}$ of $10 \%$ PVP solution in water. An enzyme, urease or GOD, and a lysine-rich polypeptide. BSA or poly-t-lysine, were added to the PVP-BASC solution. An enzyme membrane was formed by; (1) the spin-coating of the enzyme-PVP solution on the FET at 2000 r.p.m. for 30 $s,(2)$ the UV-irradiation on a limited area around the gate surface $(0.2 \times 1 \mathrm{~mm})$ for $120 \mathrm{~s}$, (3) the development in $3 \%$ glutaraldehyde solution for $5 \mathrm{~min}$ and (4) the immersion of the FET into $0.1 \mathrm{M}$ glycine solution for 5 min. The spin-coating was done with a Kyowa Riken (Tokyo, Japan) K359SD-270 spinner and the two gate surface of the FET was about $15 \mathrm{~mm}$ apart from the spinning axis. The UV-irradiation was done with Union Optical (Tokyo, Japan) Type ST exposure equipment with a Hoya (Tokyo, Japan) UV-35 cut-off filter.

\section{Apparatus}

The drain-source voltage of each FET element was set at $3.0 \mathrm{~V}$ and the gate voltage at $-1.0 \mathrm{~V}$. The substrate was biased at $5.0 \mathrm{~V}$. The differential output voltage between the FET element with an enzyme membrane and the bare one was measured by the source follower mode circuit. ${ }^{9}$

The schematic diagram of the continuous flow apparatus used to evaluate the enzyme-modified FET sensors is illustrated in Fig. 1a. The enzyme-modified 
FET sensor (Fig. 1a, S) is put into a flow-through sensor cell (SC) whose temperature is controlled by a water bath (WB). The detailed structure of the sensor cell is depicted in Fig. 1b. The inner-volume of the cell is $0.3 \mathrm{ml}$. Phosphate buffer solutions $(0.02 \mathrm{M}, \mathrm{pH}$ 6.9) with (AS) and without urea or glucose as a substrate (WS) were pumped alternately to the flow-through cell at a flow rate of $2 \mathrm{ml} / \mathrm{min}$. To avoid bacterial degradation, $0.05 \%$ sodium azide was added to phosphate buffer solutions. Measurements were done at $37^{\circ} \mathrm{C}$.

To measure the response time of the enzymemodified FET, batchwise experiments were also done. In this case, the FET sensor was immersed in $20 \mathrm{ml}$ phosphate buffer in a $50 \mathrm{ml}$ beaker. The solution was stirred with a magnetic stirrer. The response was measured by adding an appropriate amount of a concentrated substrate solution.

\section{Results and Discussion}

\section{Glucose sensitive FET sensor}

A PVP-BASC solution containing $5 \mathrm{mg}$ GOD and 5 mg BSA per $100 \mu \mathrm{l}$ was used to give a GOD membrane. Detailed description will be given elsewhere for optimizing the composition of the GODphotopolymer mixture. ${ }^{13}$

Figure 2 shows the response curves of the glucose sensor over a range of concentrations of glucose. The response curve obtained under batchwise condition instead of using the flow-through cell is depicted in Fig. $2 \mathrm{~b}$. The $100 \%$ response time is around $4 \mathrm{~s}$. The thickness of the GOD membrane could not be measured by

(a) glucose/mg dl-1

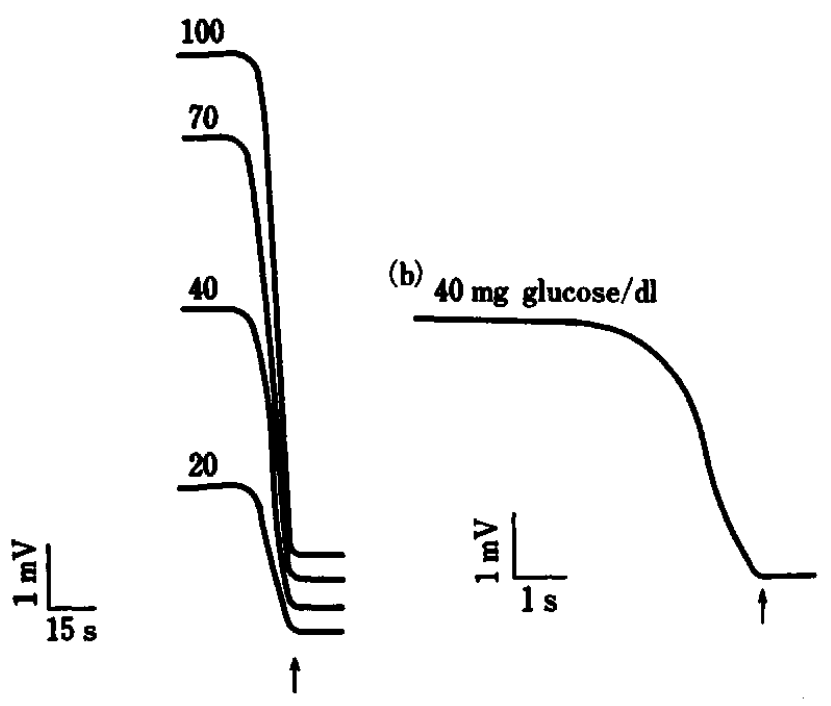

Fig. 2 Response curves of glucose sensitive FET sensor. a) using continuous flow apparatus. An arrow indicates onset of analyte solution flow. b) in a batchwise. An arrow indicates addition of glucose.

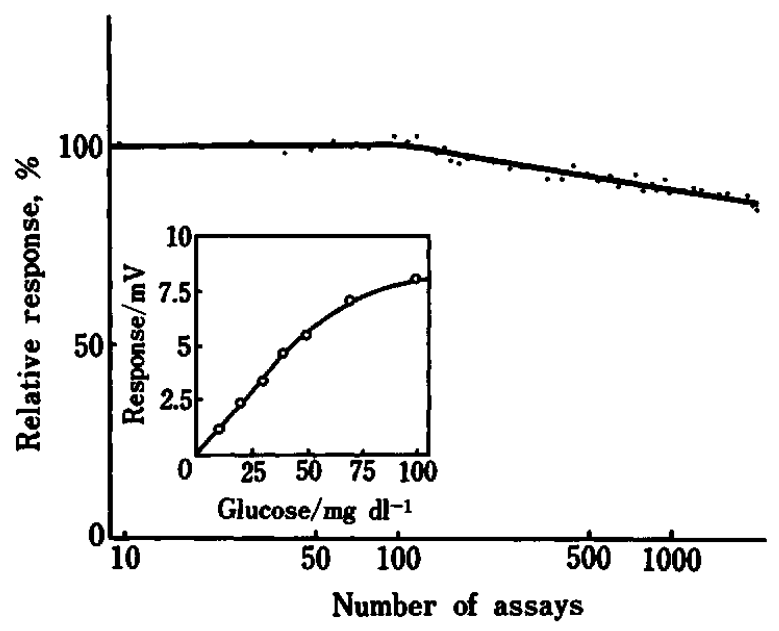

Fig. 3 Long term stability of glucose sensitive FET sensor. A sample solution containing $30 \mathrm{mg} / \mathrm{dl}$ glucose is used. The inset: calibration curve of glucose sensitive FET sensor.

the stylus instrument available in our laboratory because of the structure of the FET sensor. The thickness of the GOD membrane which was formed on a FET sensor of a different structure ${ }^{6}$ was found to be $1.8 \mu \mathrm{m}$ on average. ${ }^{13}$ The thickness of GOD membrane formed on the FET sensor reported here may be almost the same. Therefore, this thin GOD membrane can account for the rapid response obtained for the FET sensor. On the other hand it is about $15 \mathrm{~s}$ in the case of the flow method. Because the inner volume of the flow-through cell was not fully minimized, possibly the glucose sensor should show more rapid response simply by decreasing the inner volume of the sensor cell. The calibration curve is linear up to $40 \mathrm{mg} / \mathrm{dl}$ as shown in the inset of Fig. 3. The reproducibility was good; the relative standard deviation (the number of measurements $=5$ ) was less than $2 \%$ over the concentration range from 10 to $100 \mathrm{mg} / \mathrm{dl}$. Figure 3 shows that the glucose-sensitive FET can be used for more than 2000 sample solutions, although the amplitude of the response decreases gradually after 100 measurements and it is $c a .85 \%$ of the initial amplitude after 2000 measurements. The detection limit was $0.8 \mathrm{mg} / \mathrm{dl}$ (signal to noise ratio $=3$ ).

\section{Urea sensitive FET sensor}

No PVP-BASC solution containing urease and BSA was able to give a mechanically strong enzyme membrane. Instead of BSA, poly-L-lysine was used as a lysine-rich polypeptide. Several urease-polylysinePVP-BASC mixtures give rectangular shaped and mechanically strong urease membranes. The results are summarized in Table 1. Table 1 shows that the more the amount of enzyme is added to the PVP-BASC solution, the bigger the urea response becomes. But the PVP-BASC solution with $10 \mathrm{mg}$ urease per $100 \mu \mathrm{l}$ gives no mechanically strong membrane (Table 1, No. 
Table 1 Optimization of urease+poly-L-lysine/PVP mixture

\begin{tabular}{cccccc}
\hline No. & $\begin{array}{c}\text { Urease/ } \\
\mathrm{mg}\end{array}$ & $\begin{array}{c}\text { Poly-lysine/ } \\
\mathrm{mg}\end{array}$ & $\begin{array}{c}\mathrm{PVP}^{\mathrm{a}} / \\
\mu l\end{array}$ & $\begin{array}{c}\text { Response }^{\mathrm{b}} / \\
\mathrm{mV}\end{array}$ & $\boldsymbol{t}_{1 / 2}^{\mathrm{c}} / \mathrm{s}$ \\
\hline 1 & 5.0 & 5.0 & 100 & 23 & 6 \\
2 & 5.0 & 2.5 & 100 & 17 & 6 \\
3 & 5.0 & 1.0 & 100 & $-\mathrm{d}$ & - \\
4 & 7.5 & 5.0 & 100 & 21 & 7 \\
5 & 7.5 & 2.0 & 100 & 35 & 6 \\
6 & 10.0 & 5.0 & 100 & $-\mathrm{d}$ & - \\
7 & 10.0 & 2.5 & 100 & $35^{\mathrm{e}}$ & 10 \\
\hline
\end{tabular}

a. $10 \%$ PVP in water with $1 \%$ BASC.

b. Response to $25 \mathrm{mg}$ urea/dl solution using flow-through cell. Average of three measurements.

c. Time required to reach half height of response. Average of three measurements.

d. Unable to have a patterned-immobilized enzyme membrane.

e. Developed in $2 \%$ glutaraldehyde solution.

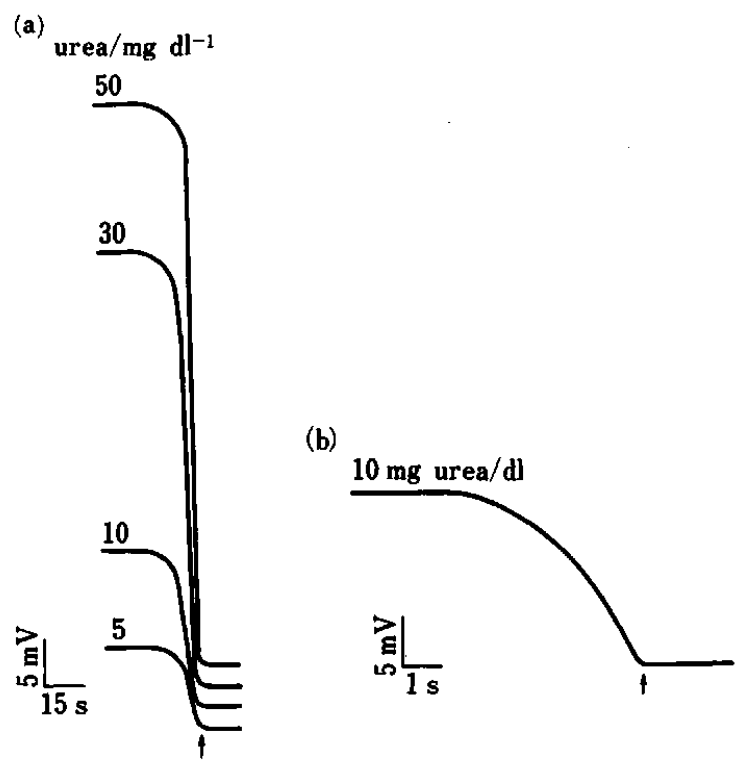

Fig. 4 Response curves of urea sensitive FET sensor. a) using continuous flow apparatus. An arrow indicates onset of analyte solution flow. b) in a batchwise. An arrow indicates addition of urea.

6) or a urease immobilized membrane which results in slower response probably due to a thicker membrane. Of these mixtures the PVP-BASC solution containing $7.5 \mathrm{mg}$ urease and $2.5 \mathrm{mg}$ poly-L-lysine per $100 \mu \mathrm{l}$ is found to be optimum in terms of the response time and amplitude.

Figure 4 shows the response curves of the urea sensor. In a batchwise its $100 \%$ response time is about $6 \mathrm{~s}$ (Fig. 4b), while it is about $25 \mathrm{~s}$ using the flowthrough cell. The response time is somewhat longer than that of the glucose sensor. The response

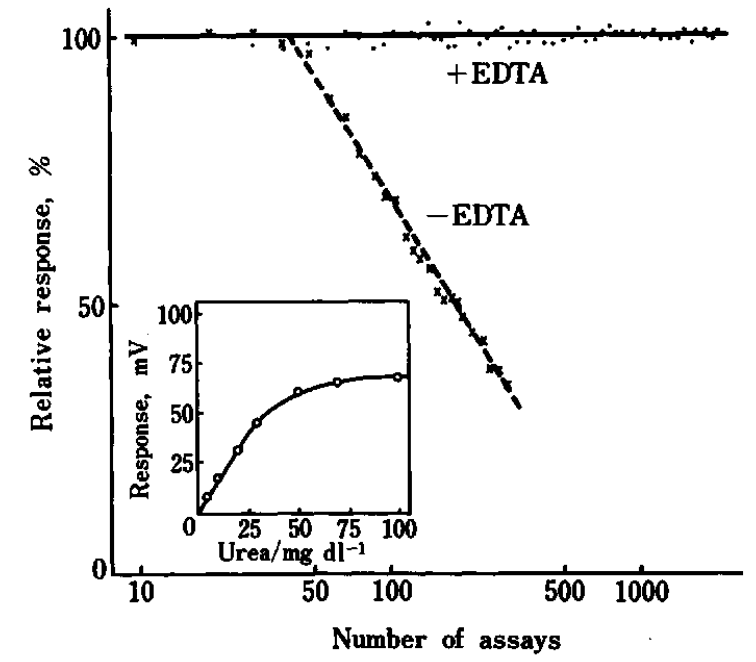

Fig. 5 Long term stability of urea sensitive FET sensor. A sample solution containing $10 \mathrm{mg} / \mathrm{dl}$ urea is used. Phosphate buffer with (solid line) and without EDTA (dotted line) are used for analyte and washing solutions. The inset: callibration curve of urea sensitive FET sensor.

amplitude of the urea sensor is about one order of magnitude larger than that of the glucose sensor. The calibration curve is shown in the inset of Fig. 5 and is linear up to $30 \mathrm{mg} / \mathrm{dl}$. The relative standard deviation (the number of measurements $=5$ ) was less than $2 \%$ over the concentration range from 10 to $100 \mathrm{mg} / \mathrm{dl}$. The detection limit of the urea-sensitive FET was $0.03 \mathrm{mg} / \mathrm{dl}$ (signal to noise ratio $=3$ ).

The long-term stability is checked using $10 \mathrm{mg} / \mathrm{dl}$ urea sample solutions as shown in Fig. 5. The response amplitude of the sensor decreases rapidly after 40 measurements without adding EDTA to the phosphate buffer solution. The decrease in the response amplitude might have been due to the following two reasons: (1) the degradation of the activity of the immobilized urease, and (2) the leakage of the immobilized urease from the membrane. An increase in the crosslinking density of the enzyme membrane should prevent the enzyme from leaking and thus make the urea sensor usable for more samples if the latter reason is the case. But neither the additional chemical crosslinking by immersing the sensor into $25 \%$ glutaraldehyde nor the additional photocrosslinking by prolonged photoirradiation after the development of the enzyme membrane could give significant improvement (adversely the additional chemical crosslinking by $25 \%$ glutaraldehyde resulted in much smaller initial amplitude). On the contrary the addition of $1 \mathrm{mM}$ EDTA to phosphate buffer makes the life of the sensor much longer and the sensor is usable for more than 2000 times, as shown in Fig. 5. Hence, the reason for the rapid decrease in the amplitude is concluded to be the degradation of the urease activity. The effect of EDTA on the durability of the urea sensor has previously been reported. ${ }^{14}$ 


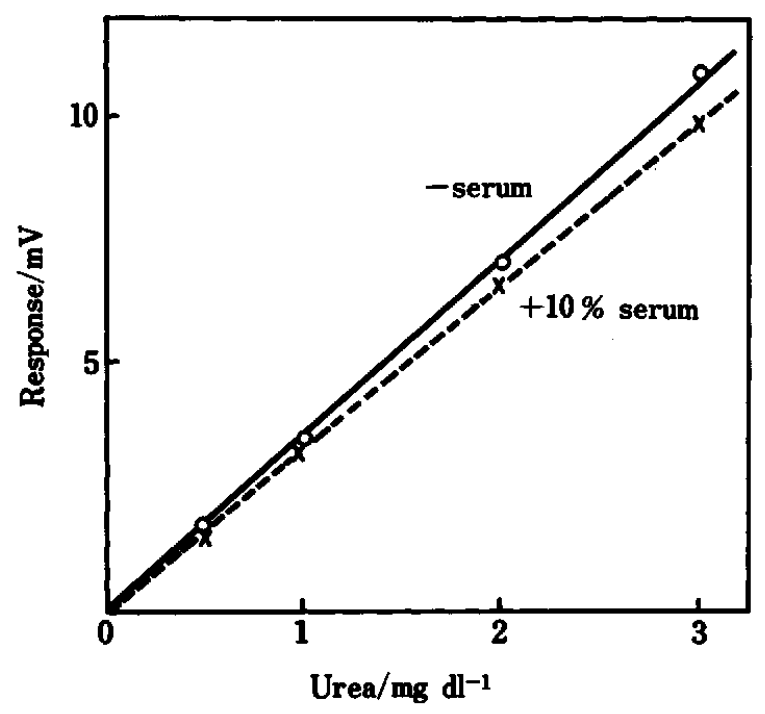

Fig. 6 Calibration curves of urea sensitive FET sensor for urea in PBS solutions with and without $10 \%$ serum.

The urea sensitive FET sensor was applied to ex vivo serum assay. For this purpose Dulbecco phosphate buffer solutions (PBS) without $\mathrm{Mg}$ and $\mathrm{Ca}, \mathrm{pH}$ 7.3, were used. The calibration curves of the urea sensor using PBS are shown in Fig. 6. The concentration range is chosen to be from 0.5 to $3 \mathrm{mg} / \mathrm{dl}$ because serum samples are to be diluted 10 times and the normal urea concentration in serum varies from 10 to $20 \mathrm{mg} / \mathrm{dl}$. The solid line shows the calibration curve for urea in PBS without serum proteins which has a higher slope than that for urea in PBS with $10 \%$ serum (the broken line). The ratio of the slopes is $\mathbf{0 . 9 2}$. The lower slope of the calibration curve for urea in 10 times diluted serum samples arises from the bigger buffering capacity of PBS with $10 \%$ serum, compared with PBS without serum proteins. Serum proteins give additional buffering capacity to the PBS buffer solution. The buffering capacity measurements for PBS with and without $10 \%$ serum was made by titrating the two PBS solutions with $0.12 \mathrm{M}$ hydrochloric acid. The results obtained showed that the ratio of the buffering capacity of PBS with and without serum was 0.91 , corresponding well with the slope ratio of the two calibration curves. The reproducibility of the urea sensor for serum urea is summarized in Table 2. It should be noted that the urea sensitive FET has practical sensitivity and precision for ex vivo serum assay, as indicated in Table 2.

In conclusion, the PVP based photopolymer containing BASC as a photocrosslinking reagent was shown to give a well defined enzyme membrane useful for a monolithic enzyme-modified FET. The photopolymer was applied to monofunctional urea and a monofunctional glucose sensor. Both sensors were evaluated
Table 2 Reproducibility of urea-sensitive FET sensor

\begin{tabular}{cccc}
\hline No. & $\begin{array}{c}\text { Conc. of urea } \\
\text { spiked in serum/ } \\
\text { mg dl }\end{array}$ & $\begin{array}{c}\text { Response } \\
\text { mV }\end{array}$ & RSD $^{\mathrm{b}}$, \% \\
\hline 1 & 5 & $1.55 \pm 0.02$ & 1.3 \\
2 & 10 & $3.20 \pm 0.04$ & 1.1 \\
3 & 20 & $6.52 \pm 0.06$ & 0.9 \\
4 & 30 & $9.99 \pm 0.13$ & 1.3 \\
\hline
\end{tabular}

a. Response of urea-sensitive FET sensor was measured after 10-times dilution of serum sample in the second column with PBS. Average \pm standard deviation of five measurements. b. Relative standard deviation.

with the $0.3 \mathrm{ml}$ flow-through cell and found to have rapid response, high sensitivity and long durability. The urea sensor was also shown to be applicable to the ex vivo serum assay with practical sensitivity and precision.

The authors are grateful to Mr. Miyazawa for giving us BASC and fruitful discussions.

\section{References}

1. S. Caras and J. Janata, Anal. Chem., 52, 1935 (1980).

2. M. J. Eddowes, D. G. Pedley and B. C. Webb, Sensors and Actuators, 7, 233 (1985).

3. S. D. Caras, J. Janata, D. Saupe and K. Schmitt, Anal. Chem., 57, 1917, 1920, 1924 (1985).

4. Y. Miyahara, T. Moriizumi and K. Ichimura, Sensors and Actuators, 7, 1 (1985).

5. J. Kimura, T. Kuriyama and Y. Kawana, Proceedings of International Conference on Solid-State Sensors and Actuators, p. 152 (1985).

6. Y. Hanazato, M. Nakako, M. Maeda and S. Shiono, Proceedings of 2nd International Meeting on Chemical Sensors, p. 576 (1986).

7. K. Shimoda, I. Takazu, T. Nagakura, Y. Miyazawa, T. Moriizumi and K. Ichimura, Proceedings of Symposium of the Institute of Electrical Engineers of Japan, EIM-85-48-56, p. 73 (1985).

8. Y. Hanazato, M. Nakako and M. Maeda, Proceedings of 50th Annual Meeting of the Chemical Society of Japan, I-605 (1985).

9. Y. Hanazato, M. Nakako and S. Shiono, IEEE Trans. on Electron Devices, 33, 47 (1986).

10. M. Nakako, Y. Hanazato, M. Maeda and S. Shiono, Anal. Chim. Acta, in press.

11. Y. Hanazato and S. Shiono, Proceedings of 1st International Meeting on Chemical Sensors, p. 513 (1983).

12. H. H. Weetall, Methods in Enzymology, XLIV, 134 (1976).

13. Y. Hanazato et al., in preparation.

14. D. S. Papastathopoulos and G. A. Rechnitz, Anal. Chim. Acta, 79, 17 (1975). 